\title{
Carotenoid blues: Structural studies on carotenoproteins
}

\author{
George Britton ${ }^{a}$, Roland J. Weesie ${ }^{a, b, c}$, David Askin ${ }^{a}$, John D. Warburton ${ }^{a}$, Lourdes \\ Gallardo-Guerrero, Frans Jos Jansen ${ }^{\mathrm{b}}$, Huub J.M. de Groot ${ }^{\mathrm{b}}$, Johan Lugtenburg, \\ Jean-Paul Cornard ${ }^{c}$ and Jean-Claude Merlin ${ }^{c}$ \\ "Department of Biochemistry, School of Biological Sciences, University of Liverpool, \\ Crown Street, Liverpool, L69 7ZB, UK \\ ${ }^{b}$ Leiden Institute of Chemistry, Gorlaeus Laboratories, P.O. Box 9502, 2300 RA \\ Leiden, The Netherlands \\ 'Laboratoire de Spectrochimie Infrarouge et Raman, CNRS, Université des Sciences \\ et Techniques de Lille, F-59655 Villeneuve d'Ascq, CEDEX, France
}

\begin{abstract}
Crustacyanin, the $320 \mathrm{kDa}$ astaxanthin-protein from the carapace of the lobster, Homarus gammarus, is the best known of the blue-purple carotenoproteins found in marine invertebrate animals. Reconstituted $\alpha$-crustacyanin complexes have been prepared from a range of natural and synthetic carotenoids. Only normal $\mathrm{C}_{40}$ carotenoids in the all- $E$ configuration fit into the binding site, though some variation in the ring size, shape and methylation pattern is tolerated. The $C(20)$ and $C\left(20^{\prime}\right)$ methyl groups must be present; presumably these are involved in essential steric interactions. The main structural requirement is the presence of keto groups at $C(4)$ and $C\left(4^{\prime}\right)$; these must be conjugated with the main polyene chain. Circular dichroism shows that the carotenoid chromophore experiences a chiral twist, but this is not a major factor in the spectral shift, and that the two astaxanthin molecules in the $\beta$-crustacyanin dimer are close together and show some interaction in the excited state. Resonance Raman and NMR spectroscopy of complexes containing ${ }^{13} \mathrm{C}$-labelled astaxanthins shows that the blue colour can be attributed to perturbation of the ground-state electronic structure of the carotenoid, caused by polarization of the chromophore. The results are consistent with protonation of the $\mathrm{C}(4)$ and $\mathrm{C}\left(4^{\prime}\right)$ keto groups, but the magnitude of the polarization effect is not the same in the two halves of the molecule.
\end{abstract}

\section{INTRODUCTION}

Interactions between carotenoids and proteins are of great physiological importance in living organisms. The carotenoids are usually much more stable in vivo than when they are isolated, and can be transported and function in a predominantly aqueous environment. In photosynthetic systems, the carotenoids are located, with chlorophylls or bacteriochlorophylls, in pigment-protein complexes to ensure the precise positioning and orientation that are essential for efficient energy transfer. In these complexes, the electronic structure of the carotenoid chromophore, as indicated by $\lambda_{\max }$, shows little change. The relationship between structure of pigment-protein complexes and functioning of carotenoids in photosynthesis has been discussed in many reviews including progress reports presented at these Symposia (refs. 1-4).

This review concentrates on the carotenoproteins, which are commonly found in marine invertebrate animals and are responsible for green, purple or blue colours, in contrast to the yellow, orange or red of the free carotenoid. A familiar and striking example is provided by the lobster Homarus gammarus which, when alive, is slate-blue in colour but, on cooking, becomes bright orange-red. The red colour is due to the carotenoid astaxanthin (3,3'-dihydroxy- $\beta, \beta$-carotene-4,4'-dione) (1) which is liberated when the cooking process denatures the natural blue pigment of the carapace, the astaxanthin-protein $\alpha$-crustacyanin. 
<smiles>CC1=C(/C=C/C(C)=C/C=C/C=C/C=C/C=C(Br)/C=C/C=C(C)/C=C/C2=C(C)C(=O)C(O)CC2(C)C)C(C)(C)CC(O)C1=O</smiles>

1

Although such complexes are well known, the nature of the molecular interactions by which the protein causes the large shift in the absorption spectrum of the carotenoid has remained a mystery. The effect on the absorption spectrum is substantial; $\alpha$ crustacyanin has $\lambda_{\max }$ at $c a 630 \mathrm{~nm}$ compared with $c a 480 \mathrm{~nm}$ for free astaxanthin, i.e. a bathochromic shift of $c a 150 \mathrm{~nm}$ (Fig. 1). In energy terms, this corresponds to a difference of $4960 \mathrm{~cm}^{-1}$, which is comparable to that in the similar retinal-proteins, such as the visual pigments and bacteriorhodopsin. In the latter complexes, the chromophore molecule, retinal, is bound to the protein covalently as a protonated Schiff base. In crustacyanin and the other carotenoproteins, however, the interactions are non-covalent, but are nevertheless stable so that the isolated complexes maintain their blue colour almost indefinitely.

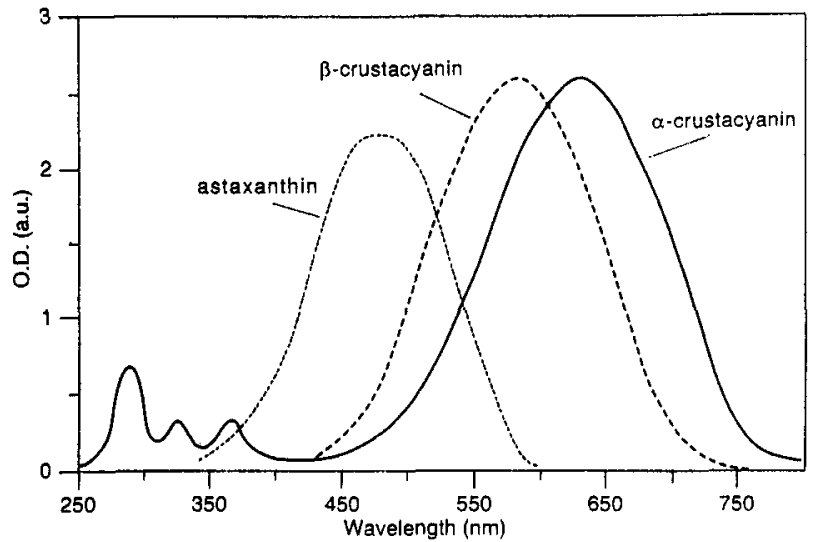

Fig. 1. UV/Visible spectra of astaxanthin (in dimethylformamide) and of $\alpha$-crustacyanin and $\beta$ crustacyanin (in $0.05 M$ sodium phosphate $\mathrm{pH} 7.0$ ).

Details of the protein structure of crustacyanin have been described in previous Symposia (refs. 5,6). The natural $\alpha$-crustacyanin is a $320 \mathrm{kDa}$ protein consisting of eight $\beta$-crustacyanin units (ca $41 \mathrm{kDa}$ ), each of which contains two apoprotein subunits. Of the five electrophoretically distinct subunits, $A_{1}, C_{1}$ and $C_{2}$ are ca $21 \mathrm{kDa}, \mathrm{A}_{2}$ and $\mathrm{A}_{3}$ each $c a 19 \mathrm{kDa}$. One $\beta$-crustacyanin molecule is formed by the association of one 21 $\mathrm{kDa}$ and one $19 \mathrm{kDa}$ subunit in combination with two molecules of astaxanthin (refs. 7,8). The most abundant subunits, $A_{2}$ (CRTA) and $C_{1}$ (CRTC), show significant sequence homology (about 25\%) with mammalian retinol-binding protein and other hydrophobic ligand carrier proteins and are considered to belong to the lipocalin superfamily of proteins (refs. 9-11). From the primary sequences, Zagalsky and coworkers (refs. 6-12) have described a computer-generated model of $\beta$-crustacyanin, in which each subunit contains four $\beta$-pleated sheet regions that form a $\beta$-barrel, and the astaxanthin molecule is positioned with one end in the apolar interior of the barrel. According to this model, the other end of the astaxanthin projects out into the surrounding medium so that, when the two subunits combine, the dimer forms a capsule-like structure enclosing the two astaxanthin molecules.

There is a demand for a water-soluble, natural blue pigment for commercial use as a colorant for food products, etc. Other natural blue pigments, such as anthocyanins, generally have poor colour stability. The idea of reproducing the effects that produce the blue colour of the carotenoproteins is therefore attractive. With this in mind, an interdisciplinary study has been undertaken to elucidate the nature of the proteincarotenoid interactions that are responsible for the large bathochromic shift in $\alpha$-crustacyanin. This review mainly describes a summary of progress achieved by this study. It builds upon an earlier report presented at the 6th Symposium at Liverpool in 1981 (ref. 13) and complements the surveys of the protein structure of crustacyanin presented by Zagalsky at the Boston and Trondheim meetings (refs. 5,6). 


\section{STRUCTURAL AND SPECTROSCOPIC PROPERTIES}

\section{Reconstitution: structural requirements for protein binding}

Information obtainable from spectroscopic studies on natural $\alpha$-crustacyanin is limited and is insufficient to reveal details of the important molecular interactions. Binding of the carotenoid to the protein is not covalent, and methods have been devised for removing the carotenoid under mild conditions and then forming reconstituted $\alpha$-crustacyanin complexes with added carotenoids or with labelled astaxanthins for detailed spectroscopic study (ref. 14). The availability of a range of natural and synthetic carotenoids (2-27) has enabled a detailed study of the structural features that are essential for the carotenoid to be bound to the apoprotein, for the apoprotein subunits to aggregate to form a multimeric complex, and for the interactions that cause the bathochromic shift, as assessed from the yield, size and UV/visible absorption spectrum of the product.

\section{Molecular size and shape}

No great variation in the overall shape and size of the carotenoid molecule is tolerated. Some carotenoid homologues with astaxanthin or astacene end groups but with longer or shorter polyene chains $\left(e . g . \mathrm{C}_{38}\right.$, $\mathrm{C}_{42}, \mathrm{C}_{44}, \mathrm{C}_{45}$ analogues) may be able to associate with the apoprotein, but no aggregation to $\beta$-crustacyanin or $\alpha$-crustacyanin occurs and no products with bathochromically shifted spectra are formed. Only all- $E$ (alltrans) isomers can be bound; the binding site will not accommodate $Z$ (cis) isomers. The acetylenic derivatives 7,8-didehydroastaxanthin (2), 15,15'-didehydroastaxanthin (3) and 7,8,7', '8'-tetradehydroastaxanthin (4), in which the main carbon skeleton deviates from linearity, can form $\alpha$-crustacyanin complexes, but in low yield and with a reduced spectral shift. Because of the altered molecular shape these molecules are not positioned optimally in the binding site.

\section{Oxygen functions}

The keto groups at $\mathrm{C}(4)$ and $\mathrm{C}\left(4^{\prime}\right)$ are essential for the formation of $\alpha$-crustacyanin-type complexes. Hydroxy groups at these positions are not effective. Adonixanthin (5, with only one $\mathrm{C}(4)$ keto group), the 3,3'-diol zeaxanthin (6), the 4,4'-diol isozeaxanthin ( 7 ) and the 3,4,3',4'-tetrol crustaxanthin (8) do not give blue complexes. The efficiency with which the $4,4^{\prime}$-diketocarotenoids bind is greater when hydroxy groups are present at $\mathrm{C}(3)$ and $\mathrm{C}\left(3^{\prime}\right)$. Thus astaxanthin binds more efficiently that adonirubin (9, one $\mathrm{C}(3)$ hydroxy group) and canthaxanthin (10, no hydroxy groups). The orientation of these hydroxy groups, i.e. the chirality at $\mathrm{C}(3)$, is not important; $\left(3 R, 3^{\prime} R\right)-,\left(3 R, 3^{\prime} S\right)$ - and $\left(3 S, 3^{\prime} S\right)$-astaxanthin all give similar $\alpha$ crustacyanin products in similar yields. The hydroxy groups are not involved in the spectral shift mechanism but the increased polarity may make it easier for the end group to be positioned correctly in the binding site. The keto groups must be conjugated with the polyene chain; in the retro analogues $(11,12)$ of astaxanthin and canthaxanthin, respectively, conjugation is broken, and these compounds do not form spectrally shifted complexes. Keto groups at $\mathrm{C}(3)$ and $C\left(3^{\prime}\right)$ are not effective, even when conjugated; $\beta, \beta$-carotene-3,3'dione (13), rhodoxanthin (14), and isoastaxanthin (15), an analogue in which the keto groups are at $\mathrm{C}(3)$ and $\mathrm{C}\left(3^{\prime}\right)$ and the hydroxy groups at $\mathrm{C}(4)$ and $\mathrm{C}\left(4^{\prime}\right)$, do not form blue complexes. $\beta, \beta$-Carotene-2,2'dione (16) does not form a complex but when conjugation extends to the $C(2)$ keto groups, i.e. in $3,4,3^{\prime}, 4^{\prime}$-tetradehydro- $\beta, \beta$ carotene-2,2'-dione (17), a blue complex is given. By rotation about the $\mathrm{C}(6,7)$ bond it is possible for this compound to adopt a conformation in which the $\mathrm{C}(2)$ keto group can occupy the same spatial position as the $\mathrm{C}(4)$ keto group of astaxanthin (Scheme 1).
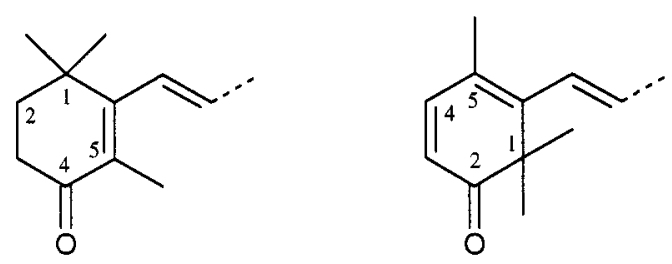

Scheme 1 

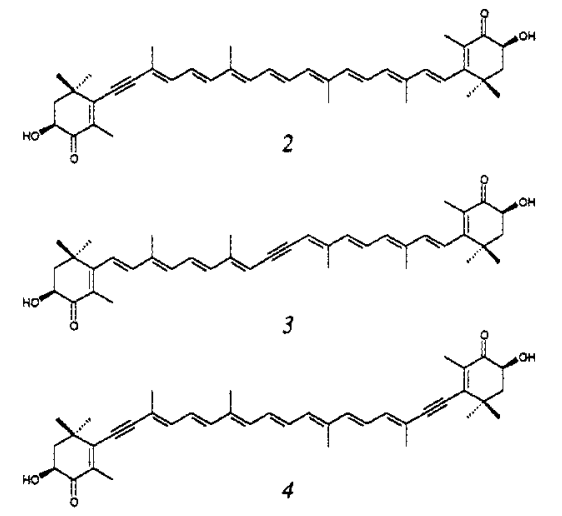

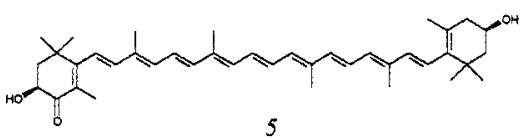

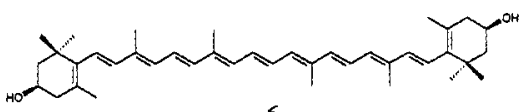<smiles>CC1=C(/C(C)=C/C=C/C(C)=C/C=C/C=C/C(C)=C/C=C/C(C)=C/C=C/C=C(C)/C=C/C2=C(C)[C@H](O)CCC2(C)C)C(C)(C)CCC1O</smiles>

On<smiles>CCCCCCCCCCCCCCCCC(C)C(C)C(C)C</smiles>

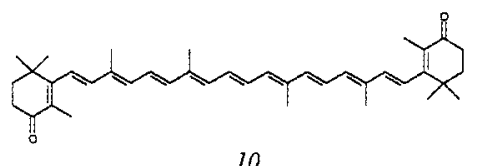<smiles>CCCCCCCCCCCCCCCCCCC(C)C(C)C(C)C</smiles>

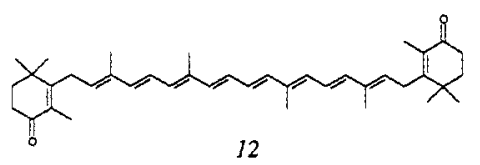

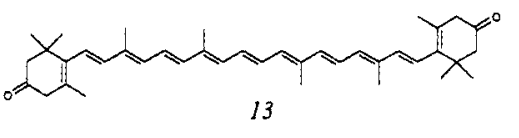

(2)<smiles>CC(C)C(C)C(C)CCCCCCCCCCCCCCCCCC(C)C(C)C(C)C</smiles>

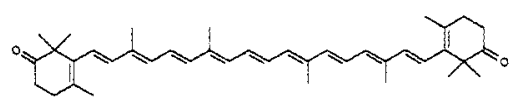

16

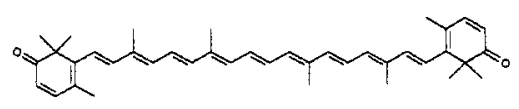

17

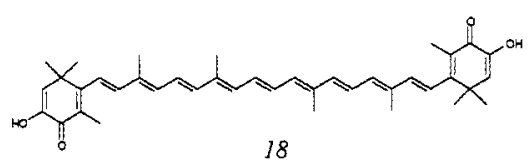

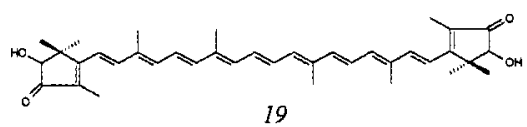

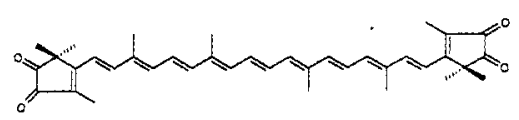

20

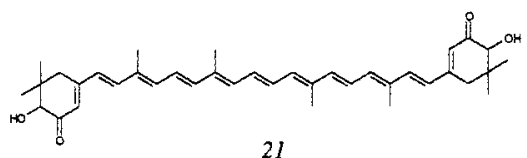<smiles>CC(C)C(C)C(C)CCCCCCCCCCCCCCCCCC(C)C(C)C(C)C</smiles>

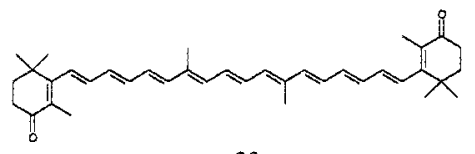

23

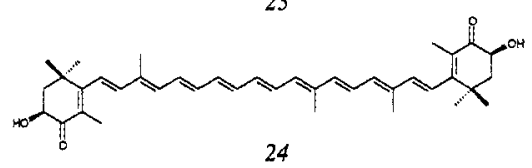

$x_{0}$

${ }_{0}$

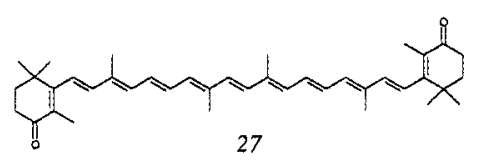




\section{Ring size and shape}

The size and shape of the cyclic end groups can be modified to some extent without greatly affecting the binding. Thus astacene (18), in which the rings are more nearly planar than those of astaxanthin, gives a similar blue complex. Actinioerythrol (19) and violerythrin (20), which have planar $\mathrm{C}_{5}$ rings, bind efficiently and give products with a large spectral shift. In the case of violerythrin $\left(\lambda_{\max } 578 \mathrm{~nm}\right)$ the spectral shift of $5354 \mathrm{~cm}^{-1}(259 \mathrm{~nm})$ results in a product with $\lambda_{\max }$ in the near infra-red, at $837 \mathrm{~nm}$. Substantial modification of the ring methylation pattern can be tolerated. 'Isonorastaxanthin' (21) gives a blue complex, though in low yield and with a reduced spectral shift of $104 \mathrm{~nm}$. In the appropriate conformation of the 2-keto-3,4didehydro- $\beta$-ring mentioned above (Scheme 1), the methyl groups are positioned differently from those of astaxanthin. Steric constraints in the vicinity of the rings therefore appear not to be great.

\section{Sidechain methyl groups}

The methyl substituents at $\mathrm{C}(9)$ and $\mathrm{C}\left(9^{\prime}\right)$ (i.e. $\mathrm{C}(19), \mathrm{C}\left(19^{\prime}\right)$ ) are not important for binding; 19,19'dinorastacene (22) and 19,19'-dinorcanthaxanthin (23) form blue complexes. The methyl substituents at $\mathrm{C}(13)$ and $\mathrm{C}\left(13^{\prime}\right)$ (i.e. $\mathrm{C}(20), \mathrm{C}\left(20^{\prime}\right)$ ), however, must both be present and in the correct positions in order for a blue complex to be formed. 20-Norastaxanthin (24), 20,20'-dinorastacene (25), 20,20'dinorcanthaxanthin (26) and 14,14'-dimethyl-20,20'-dinorcanthaxanthin (27) do not form spectrally shifted complexes. Presumably these $\mathrm{C}(20)$ and $\mathrm{C}\left(20^{\circ}\right)$ methyl groups are involved in essential steric interactions that maintain the molecule and chromophore in the correct position and conformation to maximize the interactions responsible for the spectral shift.

\section{Circular dichroism}

The $\mathrm{CD}$ of a free carotenoid is a property of the whole molecule and is determined by the chirality of the helical twist of the chromophore (ref, 15). In astaxanthin, the chirality at $\mathrm{C}(3)$ and $\mathrm{C}\left(3^{\prime}\right)$ determines the preferred ring conformation which in turn determines the ring-chain torsion angle. This generates a helical twist in the chromophore which is of opposite chirality for $\left(3 R, 3^{\prime} R\right)$-astaxanthin and ( $\left.3 S, 3^{\prime} S\right)$-astaxanthin. Under the same conditions, these isomers therefore have opposite (mirror-image) CD spectra while the meso ( $3 R, 3$ ' $S$ ) isomer is optically inactive. For free carotenoids, including astaxanthin, $\mathrm{CD}$ in the main visible region absorption bands is generally very weak but the spectra are characterized by a series of bands of alternating sign in the UV region (Fig. 2). In the CD spectrum of natural $\alpha$-crustacyanin there are again several bands of alternating sign in the UV region but the main feature is now strong CD in the main visible region absorption band (Fig. 2). The CD spectrum of the $\beta$-crustacyanin dimer is similar to that of $\alpha-$ crustacyanin, allowing for the difference in $\lambda_{\max }$, but is of somewhat lower amplitude. In both cases, the main $C D$ band shows a change of sign at $\lambda_{\max }$ that is attributed to exciton splitting and shows that the chromophores of the two astaxanthin molecules in each $\beta$-crustacyanin dimer are in close proximity and interact energetically. Asteriarubin, a purple, $43 \mathrm{kDa}$ carotenoprotein from the starfish Asterias rubens (refs. 16-18) contains only one carotenoid molecule, and shows no such exciton interaction; the CD spectrum matches the absorption spectrum closely in the visible region.

Reconstituted $\alpha$-crustacyanin complexes containing the $\left(3 R, 3^{\prime} R\right),\left(3 R, 3^{\prime} S\right)$ and $\left(3 S, 3^{\prime} S\right)$ forms of astaxanthin gave $C D$ spectra that were virtually identical in position, sign and amplitude and were very similar to the spectrum of natural $\alpha$-crustacyanin. A range of reconstituted $\alpha$-crustacyanin complexes containing different carotenoids all gave very similar CD spectra, including complexes containing the optically inactive compounds astacene (18) and canthaxanthin (12). Structural modifications such as alterations in ring shape and size (e.g. actinioerythrol, 19) or absence of sidechain methyl groups (19,19'dinorastacene, 22) made virtually no difference to the $C D$ spectrum. In the complexes, therefore, the $C D$ must be a property of the chiral twist imposed on the chromophore by the protein; the intrinsic chirality of the carotenoid is no longer a decisive factor.

When heated to $60^{\circ} \mathrm{C}, \alpha$-crustacyanin undergoes a reversible colour change from blue to red as $\lambda_{\max }$ shifts from $630 \mathrm{~nm}$ to $c a 460 \mathrm{~nm}$. A similar shift in wavelength was seen for the main $\mathrm{CD}$ band, which remained strong and retained the exciton splitting. The interactions responsible for the spectral shift can therefore be 
disrupted by heating even though the two astaxanthin molecules remain in close proximity within the protein and the interactions responsible for the chiral twist of the chromophore are not disrupted.
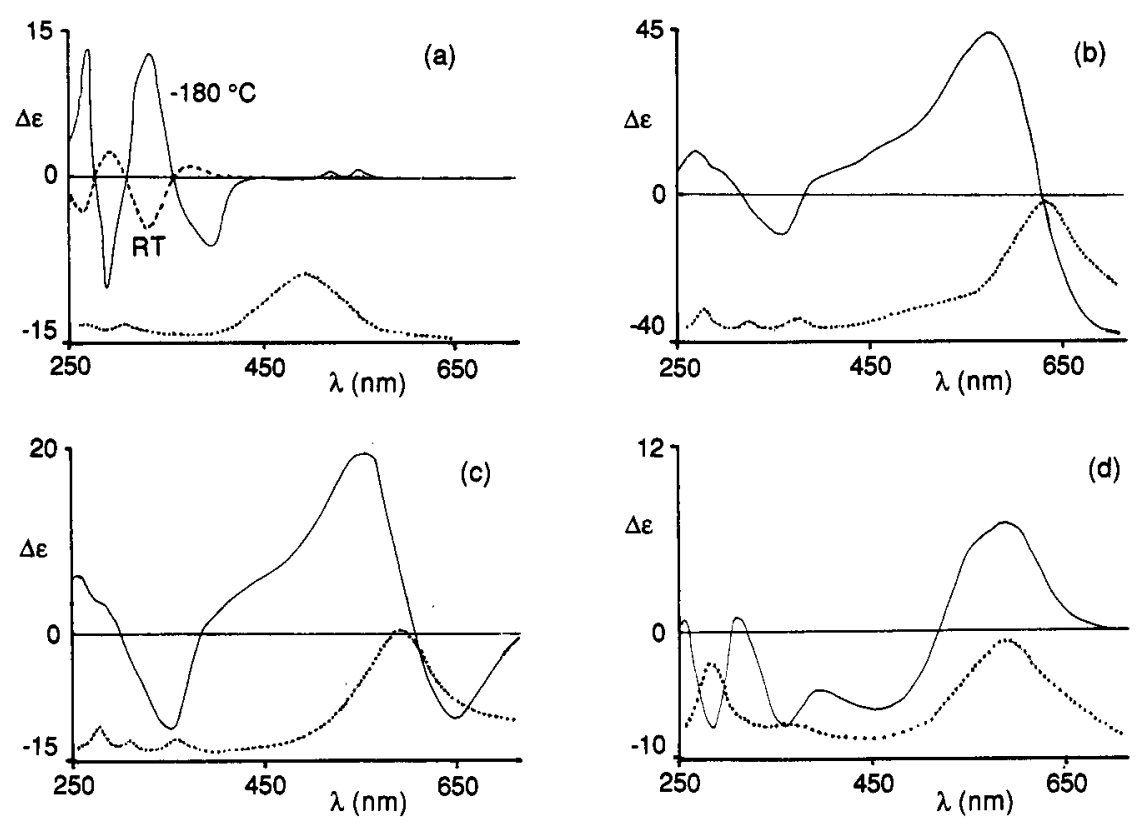

Fig. 2. CD spectra of (a) (3S,3'S)-astaxanthin, (b) natural $\alpha$-crustacyanin, (c) $\beta$-crustacyanin and (d) natural asteriarubin. The UV-Vis spectra are shown (…) for comparison.

\section{Resonance Raman spectroscopy}

Resonance Raman spectroscopy provides a method for investigating the structure of the chromophore within the complex. Raman intensities are a property of both the ground and excited electronic states, but the Raman frequencies are a property only of the electronic ground state of the molecule and therefore provide information about ligand-protein interactions that affect the ground state structure of the chromophore.

\section{Features of the resonance Raman spectrum of free astaxanthin}

Excitation into the $\pi-\pi *$ transition of the conjugated polyene chain with monochromatic light of $488.1 \mathrm{~nm}$ wavelength gives rise to very intense spectral features in the resonance Raman spectrum of astaxanthin (Fig. $3)$. The most intense line, at $1523 \mathrm{~cm}^{-1}\left(\nu_{1}\right.$ mode), is assigned to $\mathrm{C}=\mathrm{C}$ stretching vibrations of the polyene chain; all $\mathrm{C}=\mathrm{C}$ bonds stretch approximately in-phase and displacements are longer in the central part of the polyene chain and smaller towards the ends (ref. 19). Other main features are the $v_{2}$ mode at $1159 \mathrm{~cm}^{-1}$, the $v_{3}$ mode at $1008 \mathrm{~cm}^{-1}$ and the 'fingerprint region' $\left(1150-1400 \mathrm{~cm}^{-1}\right.$ ) containing weak lines that are sensitive to the nature of the carotenoid end groups and the geometry of the polyene chain (refs. 19,20). There is an inverse correlation between the $v_{1}$ mode, i.e. the $\mathrm{C}=\mathrm{C}$ stretching vibration frequency of the polyene chain and the UV/visible absorption maximum $\left(\lambda_{\text {mix }}\right)$ of the carotenoid chromophore (refs. 21-23).

\section{$\underline{\text { Resonance Raman spectrum of natural } \alpha \text {-crustacyanin }}$}

For natural $\alpha$-crustacyanin and $\beta$-crustacyanin, the $v_{1}$ mode is shifted from 1523 to $1492 \mathrm{~cm}^{-1}$ and 1498 $\mathrm{cm}^{-1}$, respectively (Fig. 3). These values fit the $1 / \lambda_{\max } v s v_{\mathrm{C}=\mathrm{c}}$ plot, showing that it is the electronic ground state which is perturbed by increased $\pi$-electron delocalization. Changes in the $v_{2}$ and $v_{3}$ modes are small. The absence of hydrogen out-of-plane modes in the $800-950 \mathrm{~cm}^{-1}$ region argues against a large proteininduced distortion of the central part of the polyene chain, but marked differences are seen in the fingerprint region, indicating that binding causes a change in the geometry of the molecule overall. 

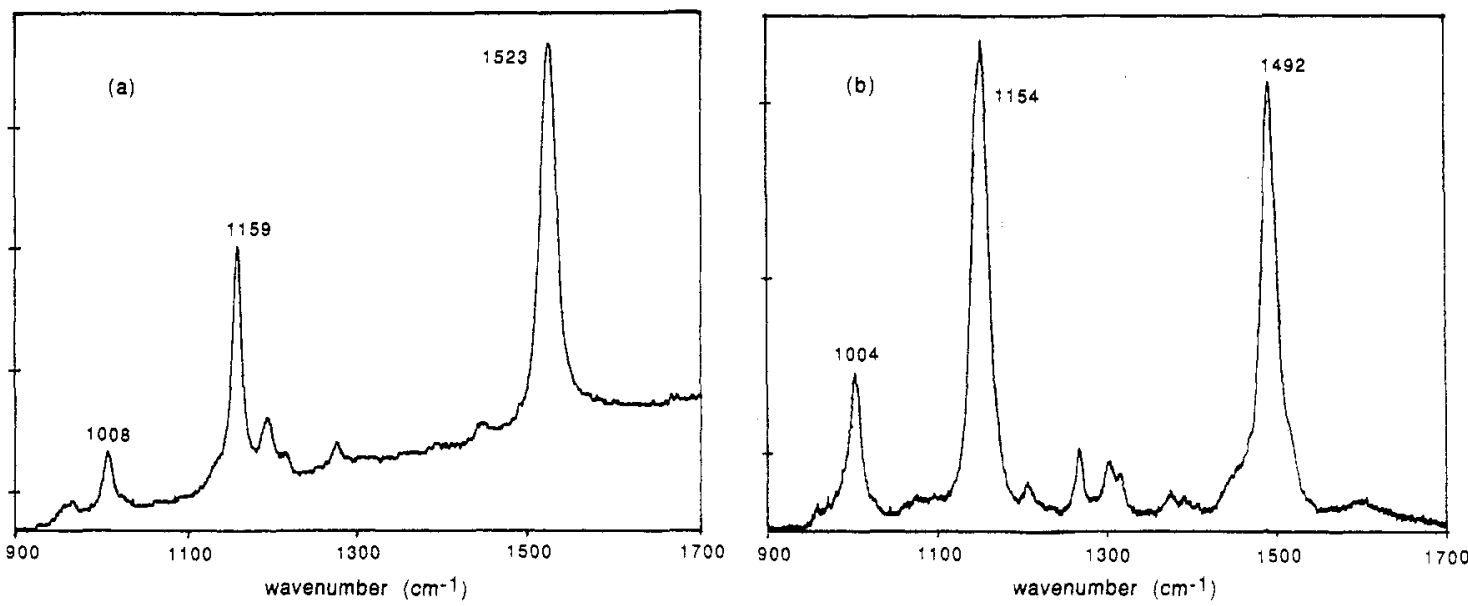

Fig. 3. Resonance Raman spectra of (a) astaxanthin (excitation wavelength $488 \mathrm{~nm}$ ) and (b) $\alpha$-crustacyanin (excitation wavelength $647 \mathrm{~nm}$ ).

\section{Resonance Raman spectra of ${ }^{13} \mathrm{C}$-labelled astaxanthins}

The availability of ${ }^{13} \mathrm{C}$-labelled astaxanthins has allowed the normal mode analysis made by Saito and Tasumi (ref. 19) to be refined, and new, localized modes to be identified and used to derive information about the effect of protein binding on parts of the astaxanthin chromophore. The ${ }^{13} \mathrm{C}$-labelled samples that were prepared for the NMR study (refs. 24,25) (see below), were also used in the resonance Raman work. For the free astaxanthins, the $v_{1}$ mode vibrations involving the heavier ${ }^{13} \mathrm{C}$ atoms shift to lower frequency and are revealed as new, localized vibrations, allowing more precise assignment. In particular, the spectra of $\left[13,13,-{ }^{13} \mathrm{C}_{2}\right]-,\left[14,14,{ }^{13} \mathrm{C}_{2}\right]-$ and $\left[15,15^{\prime}-{ }^{13} \mathrm{C}_{2}\right]$-astaxanthin (Fig. 4) showed that the ${ }^{13} \mathrm{C}(13)=\mathrm{C}(14)$, $\mathrm{C}\left(14^{\prime}\right)={ }^{13} \mathrm{C}\left(13^{\prime}\right)$ vibration frequency shifted downfield to $1509 \mathrm{~cm}^{-1}$, the $\mathrm{C}(13)={ }^{13} \mathrm{C}(14),{ }^{13} \mathrm{C}\left(14^{\prime}\right)=\mathrm{C}\left(13^{\prime}\right)$ frequency to $1500 \mathrm{~cm}^{-1}$ and the ${ }^{13} \mathrm{C}(15)={ }^{13} \mathrm{C}\left(15^{\prime}\right)$ frequency to $1508 \mathrm{~cm}^{-1}$. The remaining $\mathrm{C}=\mathrm{C}$ stretch vibrations showed a small upfield shift, to 1527,1529 and $1529 \mathrm{~cm}^{-1}$ for the three labelled species, respectively. Little change was evident in the $v_{2}$ and $v_{3}$ modes for the labelled astaxanthins, though the participation of the $C(15)=C\left(15^{\prime}\right)$ stretch vibration in the $v_{2}$ mode was confirmed.

\section{Resonance Raman spectra of $\alpha$-crustacyanin containing ${ }^{13} \mathrm{C}$-labelled astaxanthin}

For $\left[13,13,-{ }^{13} \mathrm{C}_{2}\right]-,\left[14,14,-{ }^{13} \mathrm{C}_{2}\right]-$ and $\left[15,15^{\prime}-{ }^{13} \mathrm{C}_{2}\right]$-astaxanthin (Fig. 4) the lower frequency component of the $v_{1}$ mode showed a greater shift $\left(20,27\right.$ and $22 \mathrm{~cm}^{-1}$, respectively) upon complexation than did the higher frequency component $\left(\mathrm{ca} 13 \mathrm{~cm}^{-1}\right)$. This, together with the reduction in the intensity of the higher frequency component in the complexes, leads to the conclusion that, in the ground state, the electronic structure of the central part of the polyene chain, in particular around the $\mathrm{C}(13)=\mathrm{C}(14)$ and $\mathrm{C}\left(13^{\prime}\right)=\mathrm{C}\left(14^{\prime}\right)$ region, is much more perturbed than the outer parts. However, no information is given about the extreme peripheral parts of the chromophore or the end groups. No significant information about the polyene-chromophore interactions was revealed by analysis of the $v_{2}$ or $v_{3}$ modes of the labelled samples.

The Raman data generally support an electron-redistribution (polarization) mechanism as suggested by Salares et al. (ref. 26) and provide evidence against a major distortion and strain of the polyene chain to explain the spectral shift, as proposed by Buchwald and Jencks (ref. 27) though minor changes to the geometry of the chain do occur due to binding. The general features of the resonance Raman spectrum of the starfish protein asteriarubin are similar to those of $\alpha$-crustacyanin, though distinct differences are apparent in the fingerprint region (ref. 28); the geometry of the carotenoid must be different in the two 
carotenoproteins. A Raman line at $1450 \mathrm{~cm}^{-1}$ in the spectrum of $15,15^{\prime}$-didehydroastaxanthin (4), attributed to the lateral methyl group vibrations (refs. 19,29), is split into two components at $1445 \mathrm{~cm}^{-1}$ and $1465 \mathrm{~cm}^{-1}$ in the reconstituted asteriarubin, indicating that the $C(19)$ and $C(20)$ lateral methyl groups are affected differently by protein binding (ref. 28).
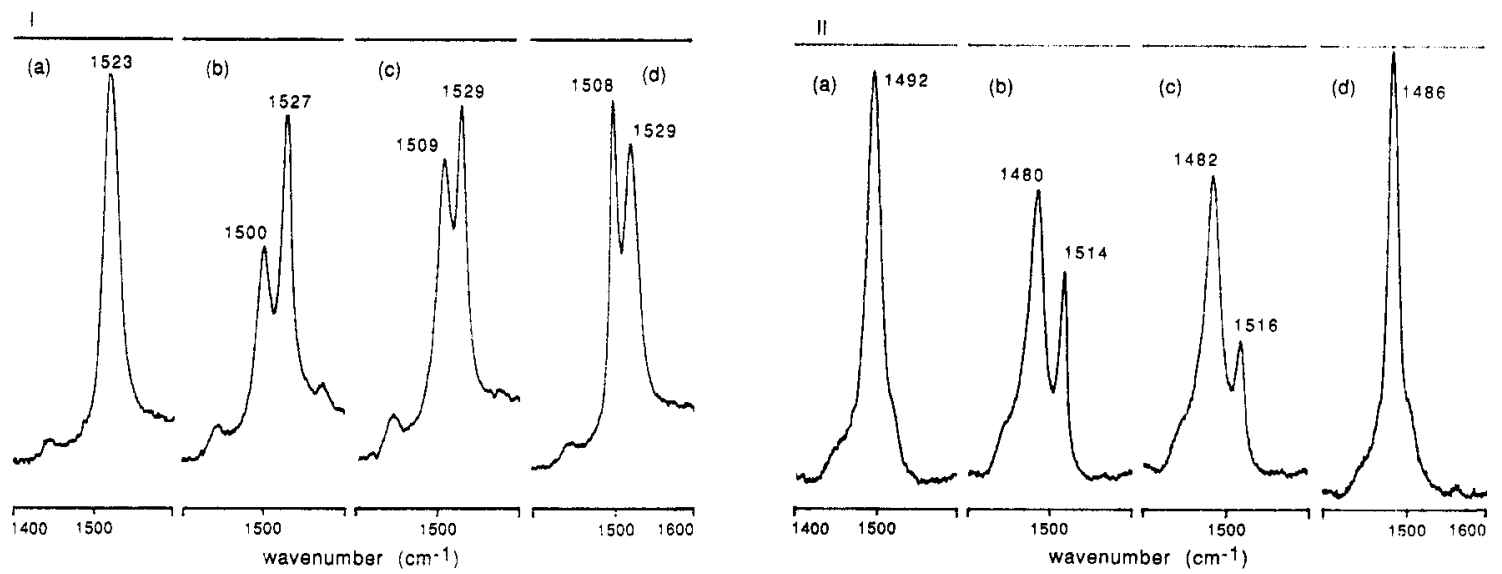

Fig. 4. Effect of ${ }^{13} \mathrm{C}$-labelling on the $v_{1}$ mode in the resonance Raman spectra of free and complexed astaxanthins. I - free astaxanthin; II - astaxanthin incorporated into $\alpha$-crustacyanin. (a) unlabelled, (b) $\left[13,13^{\prime}-{ }^{13} \mathrm{C}_{2}\right]$, (c) $\left[14,14{ }^{\prime}-{ }^{13} \mathrm{C}_{2}\right],(\mathrm{d})[15,15$ ' $\left.{ }^{13} \mathrm{C}_{2}\right]$.

\section{NMR Spectroscopy}

The strategy adopted was one which had been used successfully with the retinal-proteins, rhodopsin and bacteriorhodopsin, and with photosynthetic pigment-protein complexes in bacteria (refs. 30-32), namely to synthesize the carotenoid, in this case astaxanthin, with ${ }^{13} \mathrm{C}$ enrichment in specific positions, to incorporate it into the crustacyanin and then to investigate the reconstituted complex by solid state MAS ${ }^{13} \mathrm{C}-\mathrm{NMR}$ spectroscopy. The NMR work is described in more detail in the following paper (ref. 33).

The labelled species used were $\left[4,4{ }^{\prime}{ }^{13} \mathrm{C}_{2}\right]-,\left[12,12^{\prime}-{ }^{13} \mathrm{C}_{2}\right]-,\left[13,13^{\prime}-{ }^{13} \mathrm{C}_{2}\right]-,\left[14,14{ }^{\prime}-{ }^{13} \mathrm{C}_{2}\right]-,\left[15-{ }^{13} \mathrm{C}_{2}\right]-$, $\left[15,15^{\prime}-{ }^{13} \mathrm{C}_{2}\right]$ - and $\left[20,20{ }^{\prime}{ }^{13} \mathrm{C}_{2}\right]$-astaxanthin; synthesized as reported elsewhere (refs. 24,25). Each was incorporated into reconstituted $\alpha$-crustacyanin complexes and investigated by NMR. The first example studied was $\left[14,14{ }^{\prime}-{ }^{13} \mathrm{C}_{2}\right]$-astaxanthin (Fig. 5) (ref. 34). Significant differences were seen between the spectra of the free and complexed astaxanthin. In particular, the signal for $\mathrm{C}(14), \mathrm{C}\left(14^{\prime}\right)$ of the complex was split into two components and showed a significant downfield shift compared with that of free astaxanthin, from $134.1 \mathrm{ppm}$ to 138.0 and $140.9 \mathrm{ppm}$. The linewidths of the two components were different. In the complex, therefore, $\mathrm{C}(14)$ and $\mathrm{C}\left(14^{\prime}\right)$ of astaxanthin are in dissimilar environments, showing that the astaxanthin is influenced asymmetrically by the protein; the electron charge densities at $\mathrm{C}(14)$ and $\mathrm{C}\left(14^{\prime}\right)$ are not identical and both differ significantly from those in free astaxanthin. A similar result was obtained with $\left[12,12{ }^{\prime}-{ }^{13} \mathrm{C}_{2}\right]$-astaxanthin in crustacyanin (Table 1 ). In contrast, the signals for $\left[13,13{ }^{\prime}-{ }^{13} \mathrm{C}_{2}\right]-,\left[15-{ }^{13} \mathrm{C}_{2}\right]-$ and $\left[15,15{ }^{\prime}-{ }^{13} \mathrm{C}_{2}\right]$-astaxanthin all showed a small upfield shift due to protein binding.

Protein binding thus causes significant differences in electronic charge density and an alternating effect along the polyene chain, reversed at the centre. This is consistent with polarization from both ends of the molecule. The effect is quantitatively different in the two halves, showing that the molecule is influenced asymmetrically. As discussed in the following paper (ref. 33), calculations show that the results are consistent with a structure in which the keto groups at $\mathrm{C}(4)$ and $\mathrm{C}\left(4^{\prime}\right)$ are both protonated. Differences between the signals for the free and complexed forms of $\left[4,4,-{ }^{13} \mathrm{C}_{2}\right]$-astaxanthin are small, but calculations have shown that this corroborates the proposed structure. Unfortunately, no experimental data are yet available for the $\mathrm{C}(5)$ to $\mathrm{C}(10)$ region where changes in electronic charge density are now predicted to be greatest. 


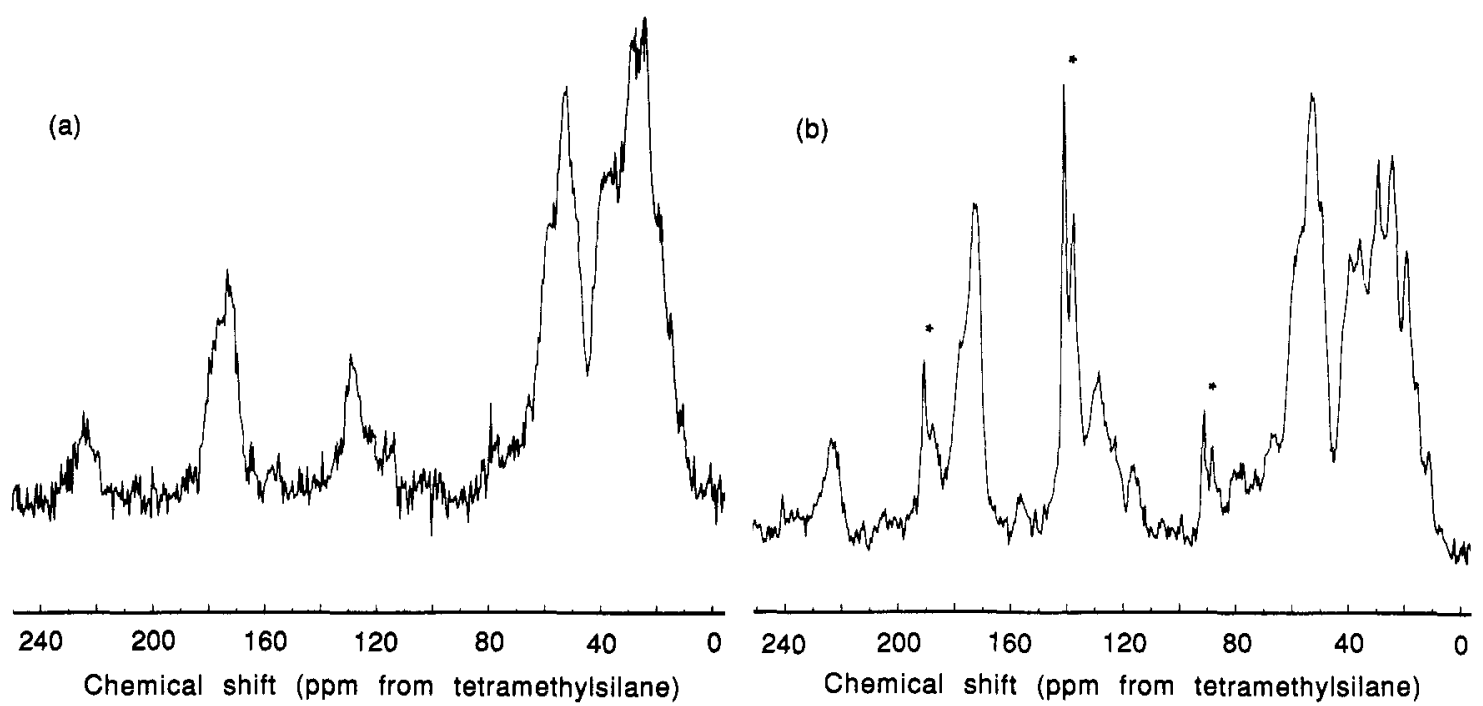

Fig. 5. MAS ${ }^{13} \mathrm{C}-\mathrm{NMR}$ spectra of $\alpha$-crustacyanin; (a) natural abundance, (b) reconstituted with $\left[14,14^{\prime}-{ }^{13} \mathrm{C}_{2}\right]$-astaxanthin.

Table 1. Comparison of the isotropic chemical shifts $\left(\sigma_{\mathrm{i}}\right)$ for several ${ }^{13} \mathrm{C}$-labelled astaxanthins in the free form and in $\alpha$-crustacyanin.

\begin{tabular}{|c|c|c|c|c|}
\hline & \multicolumn{2}{|c|}{ Astaxanthin } & \multirow{2}{*}{$\begin{array}{l}\text { Reconstituted } \\
\alpha \text {-crustacyanin }\end{array}$} & \multirow[b]{2}{*}{$\Delta \sigma_{\mathrm{i}}(\mathrm{ppm})$} \\
\hline & Solution & Solid state & & \\
\hline$\sigma_{i}\left(\left[4,4^{\prime}-{ }^{13} C_{2}\right]\right)$ & 200.3 & 201.0 & 203.4 & 2.4 \\
\hline$\sigma_{i}\left(\left[12,12,-{ }^{13} \mathrm{C}_{2}\right]\right)$ & 139.7 & 140.2 & $\begin{array}{ll}145.1 & 147.2\end{array}$ & $4.9 \quad 7.0$ \\
\hline$\sigma_{i}\left(\left[13,13,-{ }^{13} C_{2}\right]\right)$ & 136.7 & 137.1 & 135.2 & -1.9 \\
\hline$\sigma_{i}\left(\left[14,14{ }^{\prime}-{ }^{13} C_{2}\right]\right)$ & 133.8 & 134.1 & $\begin{array}{ll}138.0 & 140.9\end{array}$ & $3.9 \quad 6.8$ \\
\hline$\sigma_{i}\left(\left[15,15,-{ }^{13} C_{2}\right]\right)$ & 130.7 & 130.1 & 129.5 & -0.6 \\
\hline$\sigma_{\mathrm{i}}\left(\left[15-{ }^{13} \mathrm{C}_{2}\right]\right)$ & 130.7 & 130.2 & 129.7 & -0.5 \\
\hline$\sigma_{\mathrm{i}}\left(\left[20,20^{\prime}-{ }^{13} \mathrm{C}_{2}\right]\right)$ & 12.8 & 11.5 & 11.1 & -0.4 \\
\hline
\end{tabular}

\section{CONCLUSIONS}

To fit into the binding site of the crustacyanin protein, the carotenoid must be a normal $\mathrm{C}_{40}$ size and in the linear all- $E$ configuration, but some limited variation in the ring size, shape and methylation pattern is possible. Other structural features such as the $\mathrm{C}(20)$ and $\mathrm{C}\left(20^{\prime}\right)$ methyl groups are required for the formation of a spectrally-shifted complex, and are presumably involved in some essential steric interactions. The carotenoid chromophore experiences a chiral twist, but this is not a major factor in the spectral shift. The two astaxanthin molecules encapsulated in the $\beta$-crustacyanin dimer are close together and interact energetically. In asteriarubin only one carotenoid is present but a bathochromic shift is again generated, showing that chromophore-chromophore exciton interactions are not essential to the spectral shift. The main structural requirement for binding is the presence of keto groups at $C(4)$ and $C\left(4^{\prime}\right)$; these must be conjugated with the main polyene chain. The bathochromic shift can be attributed to perturbation of the ground state electronic structure of the carotenoid, caused by polarization of the chromophore, e.g. by protonation of the $\mathrm{C}(4)$ and $\mathrm{C}\left(4^{\prime}\right) \mathrm{C}=\mathrm{O}$ groups. The magnitude of the polarization effect is not the same in the two halves of the molecule. 
According to the proposed model of the $\beta$-crustacyanin dimer (refs. 6-12), one astaxanthin end group would be in an apolar, aprotic environment. This is not consistent with the data presented here, which would require a charged amino acid residue in close proximity to the $\mathrm{C}(4)$ keto group to bring about the protonation. The involvement of a water molecule in the protonation process, as in the retinal-proteins, is also highly likely.

\section{ACKNOWLEDGEMENTS}

The support of F. Hoffmann-La Roche, Ltd. and of the European Commission (SCIENCE contract SCICT92-0813) is gratefully acknowledged. L. Gallardo-Guerrero is very grateful to the CSIC (Spain) for her postdoctoral fellowship. We also thank Hoffmann-La Roche and Prof. Hans-Dieter Martin and Ralph Ackermann, University of Düsseldorf, for kindly providing carotenoid samples, and Dr. Peter Zagalsky, Royal Holloway, for fruitful discussions and advice on protein purification.

\section{REFERENCES}

1. A. J. Young. In Carotenoids in Photosynthesis (A. Young and G. Britton, eds.), pp. 72-95. Chapman and Hall, London (1993).

2. H. A. Frank and R. J. Cogdell. In Carotenoids in Photosynthesis (A. Young and G. Britton, eds.), pp. 252-326. Chapman and Hall, London (1993).

3. H. A. Frank, C. A. Violette, J. K. Trautman, A. P. Shreve, T. G. Owens and A. C. Albrecht. Pure Appl. Chem. 63, 109114 (1991).

4. M. Mimuro and T. Katoh. Pure Appl. Chem. 63, 123-130 (1991).

5. J. B. C. Findlay, D. J. C. Pappin, M. Brett and P. F. Zagalsky. In Carotenoids: Chemistry and Biology (N. I. Krinsky, M. M. Mathews-Roth and R. F. Taylor, eds.), pp. 75-105. Plenum Press, New York (1990).

6. P. F. Zagalsky. Pure Appl. Chem. 66, 973-980 (1994).

7. R. Quarmby, D. A. Norden, P. F. Zagalsky, H. J. Ceccaldi and R. Daumas. Comp. Biochem. Physiol. 56B, 55-61 (1977)

8. P. F. Zagalsky. Comp. Biochem. Physiol. 73B, 997-1000 (1982).

9. P. F. Zagalsky, E. E. Eliopoulos and J. B. C. Findlay. Comp. Biochem. Physiol. 97B, 1-18 (1990).

10. J. N. Keen, I. Caceres, E. E. Eliopoulos, P. F. Zagalsky and J. B. C. Findlay. Eur. J. Biochem. 197, 407-417 (1991).

11. J. N. Keen, I. Caceres, E. E. Eliopoulos, P. F. Zagalsky and J. B. C. Findlay. Eur. J. Biochem. 202, $31-40$ (1991).

12. P. F. Zagalsky, R. S. Mummery, E. E. Eliopoulos and J. B. C. Findlay. Comp. Biochem. Physiol. 97B, 837-848 (1990).

13. G. Britton, G. M. Armitt, S. Y. M. Lau, A. K. Patel and C. C. Shone. In Carotenoid Chemistry and Biochemistry (G. Britton and T. W. Goodwin, eds.), pp. 237-251. IUPAC-Pergamon, Oxford (1982).

14. P. F. Zagalsky. Methods Enzymol. 111, 216-247 (1985).

15. R. Buchecker and K. Noack. In Carotenoids. Vol. IB: Spectroscopy (G. Britton, S. Liaaen-Jensen and H. Pfander, eds.), pp. 63-116. Birkhäuser, Basel (1995).

16. A. Elgsaeter, J. D. Tauber and S. Liaaen-Jensen. Biochim. Biophys. Acta, 530, 402-411 (1978).

17. B. Renstrøm, J. D. Tauber, A. Elgsaeter and S. Liaeen-Jensen. Biochem. Syst. Ecol. 7, 147-148 (1979).

18. C. C. Shone, G. Britton and T. W. Goodwin. Comp. Biochem. Physiol. 62B, 507-513 (1979).

19. S. Saito and M. Tasumi. J. Raman Spectrosc. 14, 310-321 (1983).

20. H. Okamoto, S. Saito, H. Hamaguchi, M. Tasumi and C. H. Eugster. J. Raman Spectrosc. 15, 331-336 (1984).

21. M. E. Heyde. D. Gill, R. G. Kilponen and L. Rimai. J. Am. Chem. Soc, 93, 6776-6780 (1971).

22. L. Rimai, M. E. Heyde and D. Gill. J. Am. Chem. Soc. 95, 4493-4501 (1973).

23. V. R. Salares, N. M. Young, P. R. Carey and H. J. Bernstein. J. Raman Spectrosc. 6, 282-288 (1977).

24. F. J. H. M. Jansen, M. Kwestro, D. Schmitt and J. Lugtenburg. Recl. Trav. Chim. Pays-Bas 113, $552-562$ (1994).

25. F. J. Jansen and J. Lugtenburg. In Carotenoids. Vol. 2: Synthesis (G. Britton, S. Liaaen-Jensen and H. Pfander, eds.), pp. 233-258. Birkhäuser, Basel (1996).

26. V. R. Salares, N. M. Young, H. J. Bernstein and P. R. Carey. Biochim. Biophys. Acta 576, 176-191 (1979).

27. M. Buchwald and W. P. Jencks. Biochemistry 7, 834-843; 844-859 (1968).

28. J. C. Merlin, E. W. Thomas, C. C. Shone and G. Britton. Biochim. Biophys. Acta 913, 111-116 (1987).

29. R. J. H. Clark, N. R. D'Urso and P. F. Zagalsky. J. Am. Chem. Soc. 102, 6693-6698 (1980).

30. J. Lugtenburg, R. A. Mathies, R. G. Griffin and J. Herzfeld. Trends Biochem. Sci. 13, 388-393 (1988).

31. S. O. Smith, I. Palings, M. E. Miley, J. Courtin, H. J. M. de Groot, J. Lugtenburg, R. A. Mathies and R. G. Griffin. Biochemistry 29, 8158-8164 (1990).

32. R. Gebhard, K. van der Hoef, C. A. Violette, H. J. M. de Groot, H. A. Frank and J. Lugtenburg. Pure Appl. Chem. 63, 115-122(1991).

33. R. J. Weesie, R. Verel, F. J. H. M. Jansen, G. Britton, J. Lugtenburg and H. J. M. de Groot. Following paper.

34. R. J. Weesie, D. Askin, F. J. H. M. Jansen, H. J. M. de Groot, J. Lugtenburg and G. Britton. FEBS Letters 362, 34-38 (1995). 